\title{
Home, Parents, and Achievement Motivation: A Study of Key Home and Parental Factors that Predict Student Motivation and Engagement
}

\author{
Marianne Mansour and Andrew J. Martin \\ Faculty of Education and Social Work, University of Sydney, Australia
}

\begin{abstract}
The home and parental factors that predict achievement motivation are an important focus in research, because they are a clear point for potential educational and psychological support for students. The present study investigates the achievement motivation of high school students, in the context of parental and home factors such as home resources, in- and out-of-home parental assistance, parenting style, and parental involvement in the school. Among a sample of 100 Australian high school students, hierarchal multiple linear regression analyses were performed in order to determine the relative salience of the proposed home and parental factors predicting students' achievement motivation. Results demonstrated that over and above demographic factors such as age, gender and ethnicity, home and parental factors do indeed play a critical function in predicting student motivation and engagement. Specifically, the study reveals that home resources and parenting style are the most salient home and parental factors associated with key aspects of achievement motivation and engagement (planning, task management, teacher-student relationships - positively, and self-handicapping - negatively). These findings affirm the role of the home and parents in students' academic development. Implications for future research and practice harnessing the present findings are discussed.
\end{abstract}

I Keywords: home, parents, motivation and engagement

Academic motivation and engagement play critical roles in students' interest in and satisfaction at school, contribute to their academic achievement, and constitute influential platforms for young people's pathways beyond school (Dweck, 1986; Martin, 2002, 2007; Pintrich, 2000, 2003). Enhancing and sustaining motivation and engagement are therefore widely valued as an important element of school education (Pomerantz \& Moorman, 2007). Parents, ${ }^{1}$ educators, and researchers are continually searching for promising and beneficial practices that will improve students' motivation, engagement, and orientation towards school. Accordingly, much previous

\footnotetext{
Address for correspondence: Associate Professor Andrew J. Martin, Faculty of Education and Social Work, A35 - Education Building, University of Sydney NSW 2006, Australia.

E-Mail: a.martin@edfac.usyd.edu.au
} 
research and practice has been directed at better understanding the home, parental, and educational background factors that predict motivation and engagement. Despite the high quality and informative research that has previously demonstrated the critical role home factors play in students' motivation and engagement (e.g., Baumrind, 1966, 1991; Martin, 2003c; Pomerantz \& Moorman, 2007), relatively little research has sought to identify the salience of various home and parental factors in the one analytic model. Thus, whereas a good deal of research has shown that home is influential, there is less research that explores these factors in the one model, controlling for shared variance. The present study seeks to do so, with a view to more clearly identifying what home factors are and are not uniquely predictive of motivation and engagement.

\section{Prior Theory and Research}

Self-Determination Theory. Self-Determination Theory (SDT; Deci \& Ryan, 2000; Ryan \& Deci, 2000) makes direct and explicit statements about the link between parental factors and students' academic motivation and engagement. According to SDT, there are three key needs to be met, in order for an individual to behave in adaptive and efficacious ways. These are the need for competence, autonomy, and connectedness (Deci, Vallerand, Pelletetier \& Ryan, 1991). Competence refers to how individuals accomplish both external and internal outcomes and their success in implementing the appropriate action required to attain a desired end point (Deci et al., 1991). Autonomy is the extent to which individuals have or perceive a sense of control (or internal locus) in implementing thought-behaviour repertoires to attain a desired end point. Individuals with a high sense of autonomy tend to behave in selfregulated and self-instigated ways (Deci et al., 1991). Connectedness refers to individuals' sense of security and positive attachment to significant others (Deci et al., 1991). In the academic domain, these three dimensions are relevant to students' achievement motivation (Deci \& Ryan, 2000; Ryan \& Deci, 2000) and it is particularly in relation to the third dimension - connectedness - that the present study seeks to examine the role of parental and home factors in shaping students' academic development.

Parenting style. Examining parent-child interactions also brings into consideration the issue of parenting style and its role in predicting important outcomes for children. Parenting style can be defined as a 'constellation of attitudes toward the child that are communicated to the child and that, taken together, create an emotional climate in which the parent's behaviours are expressed' (Darling \& Steinberg, 1993, p. 488). Numerous researchers have demonstrated a link between parenting style and a child's academic and non-academic outcomes (Gigliotti \& Brookover, 1975; Grolnick \& Slowiaczek, 1994; Pomerantz \& Moorman, 2007). Of interest in the present study is the extent to which parenting style predicts achievement motivation, when considered in the context of other home factors, such as home resources, parents' involvement in the school, and tangible support offered within and outside the home.

Social Capital Theory. Social Capital Theory (SCT; Bassani, 2007) is centrally concerned with the social relations that are established within groups and the ways these relations impact various outcomes. Research has demonstrated a link between social capital and key life outcomes, such as young people's wellbeing (Bassani, 2007). 
Specifically, if relations between parents and their children are positive in nature, this has a corresponding and positive impact on young people's development. Since the bulk of SCT research has focused on general wellbeing, there is a need to consider its ideas in the academic domain and in terms of students' academic wellbeing. Hence, through a SCT lens, the present study focuses on children, the home, their parents and the nature of their inter-relationships in shaping students' academic wellbeing, assessed by way of their academic motivation and engagement.

\section{Other Predictive Factors Relevant to the Present Study}

These theories also provide indirect or implied direction on what is worth studying in an investigation of parents and home. Based on theoretical contentions, it is proposed that five such factors are important to consider: home resources, in-home parental assistance, out-of-home parental assistance, parental involvement in the school, and demographics.

Home resources. The kinds of resources students have available within their home environment can potentially assist in their educational development. These resources take various forms and can aid students in their schooling and academic endeavours in unique ways. For example, student learning can be enhanced by the availability and use of computers within the home (Fuchs \& Wobmann, 2005; Pomerantz \& Moorman, 2007). Additionally, Catan (2004) found that logistical support within the home can take the form of private study space, the availability of computers, and availability of books.

In-home parental assistance. Practical parental assistance can also be a factor shaping achievement motivation. The ways in which parents can assist their children at home include help with homework, discussing subject selection and choices, discussing academic aspirations and post-school pathways, and broader communication regarding their child's education (Pomerantz \& Moorman, 2007). Research indicates that parental assistance within the home leads to positive academic outcomes for students (Gonzalez, 2002; Pomerantz \& Moorman, 2007). Indeed, even school students themselves associate in-home parental assistance with school grades (Grolnick \& Slowiaczek, 1994). Importantly, however, most research of in-home assistance tends to focus on help with homework and assignments (Grolnick \& Slowiaczek, 1994).

Out-of-home parental assistance. Exposure to out-of-home interests and activities has also been found to facilitate various aspects of development - including academic development (Grolnick \& Slowiaczek, 1994). Potentially engaging and stimulating out-of-home pursuits include activities such as taking a child to the library, a museum, or a historical site (U.S. Department of Education, 2003). In the Australian 2006 Survey of Children's Participation and Leisure Activities, 71\% of children aged 5 to 14 years had visited a library, museum, art gallery, or a performing arts event (e.g., play or concert) at least once in the previous 12 months (Australian Bureau of Statistics, 2006). Such statistics reveal that student involvement in out-of-home activities, is a feature within the Australian context and reflects the multiple ways students can engage with cognitively and behaviourally stimulating activities.

Parental involvement in the school. Schools often encourage parental involvement because they view it as a valuable part of their students' educational experience, an 
opportunity for parents to develop positive attitudes and orientations to school, and a chance to better align school and home values and priorities (Feuerstein, 2007). Hence, in a similar fashion to parental assistance at home, the extent of parental involvement in the school may also be an indicator of adaptive parental influence regarding school, schoolwork, and their child's education (Pomerantz \& Moorman, 2007). This kind of involvement, if adaptive in nature, can positively influence how a child feels about their own involvement at school, with a subsequent impact on academically constructive outcomes such as achievement and engagement (Gonzalez, 2002). Potential involvements in the school are many and varied, ranging from assistance at school fairs, volunteering in the canteen, and attending parent-teacher interviews - with research finding these types of parental engagement positively linked to student achievement (Dempsey-Hoover et al., 2005; Pomerantz \& Moorman, 2007).

Demographic factors. In addition to exploring home and parental factors hypothesised to predict students' motivation and engagement, it is suggested that the unique contribution of these factors is also established through examining their contribution over and above that of demographic factors such as gender, age, and ethnicity. Research suggests declining levels of motivation, engagement, and achievement among boys in the past decade (see MacDonald, Saunders \& Benfield, 1999; Martin, 2003a, 2003b, 2004; Organisation for Economic Co-operation and Development, 2001; Rowe \& Rowe, 1999; Weaver-Hightower, 2003). In relation to motivation, Martin (2007) has found that boys report significantly lower levels of adaptive motivation and significantly higher levels of impeding and maladaptive motivation. Of similar importance to gender effects in motivation are age-related differences. A longitudinal study by Jacobs, Lanza, Osgood, Eccles and Wigfield (2002) found that students' self-perceptions of competence and task values declined as they got older. Martin (2001, 2003d, 2004, 2007) has also identified declines in motivation and engagement in the mid-adolescent years. Ethnicity can also play a role in student motivation, engagement, and achievement at school. A study by Glick and Marriot (2007) found that academic performance varies across ethnicities among school students. A US-based study by Coll and Magnuson (1997) found that parents from Latino, East Asian, Filipino and European backgrounds strongly value education - a belief shared by their children. Similarly, a longitudinal study by Duran and Weffer (1992) indicated that educational values (e.g., valuing of school, importance placed on learning) held by immigrants play a role in their children's achievement.

\section{Aims of the Present Study}

The central aim of this study is to investigate the role of home and parental factors in predicting achievement motivation. Key home and parental factors under investigation are home resources, in-home assistance, out-of-home assistance, parenting style, and involvement within the school. These, it is proposed, constitute a broadly-based approach to understanding how home and parent factors are linked to students' achievement motivation. Although it is proposed that home and parental factors will be influential, what is uncertain is the nature and extent of specific factors in predicting various aspects of motivation and engagement. Also unclear is their relative salience when other factors such as gender, age, and ethnicity are included in analyses. Accordingly, this study seeks to explicate the influence of multiple home and 
background characteristics on students' achievement motivation with a view to identifying factors that significantly contribute to specific dimensions of their academic motivation and engagement.

\section{Method}

\section{PARTICIPANTS}

The sample comprised $N=100$ students (48\% female; $52 \%$ male) in two high schools in the western suburbs of Sydney, Australia of whom 12\% were in Year 7, 15\% were in Year 8, 29\% were in Year 9, 25\% were in Year 10, 13\% were in Year 11, and 6\% of students were in Year 12. The mean age of students was $14.49(S D=1.55)$ years and the average number of days absent was 4 days $(S D=7.31)$ for the previous term. Over three-quarters (78\%) of students were born in Australia.

\section{MATERIALS}

The research was based on students' self-reports of academic motivation and engagement, home and parent support, and demographics. The instrument included the Motivation and Engagement Scale - High School (Martin, 2008b), home support items (from PISA; OECD, 2006), parenting style (adapted from Cohen, Dibble, \& Grawa, 1977), and additional engagement items assessing enjoyment of school, class participation, teacher-student relationship, homework completion, academic intentions and academic buoyancy (students' capacity to effectively deal with academic challenge inherent in the ordinary course of school life), developed and validated in similar research (Green, Martin, \& Marsh, 2007; Martin, 2007, 2008a; Martin \& Marsh, 2006, 2008a, 2008b).

Home, parental, and demographic factors. Dichotomous Yes/No scales were used to assess: resources within the home (from PISA 2006; e.g., 'A quiet place to study, a computer, a desk to study at'), parental assistance with educational matters and issues in the home (e.g., 'Helped prepare for a school test or similar'), whether parents had helped or encouraged the child to participate in out-of-home activities (e.g., 'Event sponsored by a religious group'), parenting style (adapted from Cohen et al., 1977; Martin, Linfoot \& Stephenson, 2000) in relation to school and learning (e.g., 'My parents listen to my views about my learning'), and parental involvement within school in the first school term (e.g., 'Attended a school function such as play or performance night'; US Department of Education, 2003). On ethnicity, participants were asked if they spoke English (0) or another language (1 - non-English-speaking background, NESB) at home. Gender was coded 0 for females and 1 for males. Age was retained as a continuous variable.

Motivation and Engagement Scale - High School (MES-HS). The Motivation and Engagement Scale - High School (MES-HS; Martin, 2008b) is an instrument that assesses student motivation and engagement through adaptive cognitive constructs, adaptive behavioural constructs, impeding/maladaptive cognitive constructs, and maladaptive behavioural constructs. Adaptive cognitions include self-efficacy (e.g., 'If my homework is difficult, I keep working at trying to figure it out'), mastery orientation (e.g., 'I feel very pleased with myself when I do well at school by working hard'), and valuing school (e.g., 'Learning at school is important'). Adaptive behaviours include persistence (e.g., 'If I don't give up, I believe I can do difficult 
TABLE 1

Descriptive Statistics and Reliability

\begin{tabular}{|c|c|c|c|c|c|}
\hline & Mean & $S D$ & Skewness & Kurtosis & Cronbach's $\alpha$ \\
\hline \multicolumn{6}{|l|}{ Adaptive cognition } \\
\hline Self-efficacy (mean /7) & 5.90 & 1.04 & -.98 & .37 & .77 \\
\hline Valuing (school) (mean /7) & 6.04 & 1.01 & -1.27 & .95 & .83 \\
\hline Mastery orientation (mean /7) & 6.13 & 0.93 & -.88 & -.28 & .81 \\
\hline \multicolumn{6}{|l|}{ Adaptive behaviour } \\
\hline Planning (mean /7) & 4.91 & 1.34 & -.39 & -.13 & .78 \\
\hline Task management (mean /7) & 5.49 & 1.24 & -.95 & 1.06 & .81 \\
\hline Persistence (mean /7) & 5.30 & 1.25 & -.63 & .00 & .84 \\
\hline \multicolumn{6}{|l|}{ Impeding cognition } \\
\hline Anxiety (mean /7) & 4.30 & 1.45 & .16 & -.56 & .74 \\
\hline Failure avoidance (mean /7) & 3.04 & 1.42 & .58 & .02 & .75 \\
\hline Uncertain control (mean /7) & 3.70 & 1.34 & -.21 & -.59 & .68 \\
\hline \multicolumn{6}{|l|}{ Maladaptive behaviour } \\
\hline Self-handicapping (mean /7) & 2.70 & 1.40 & .41 & -.84 & .76 \\
\hline Disengagement (mean /7) & 2.50 & 1.31 & .74 & -.24 & .76 \\
\hline \multicolumn{6}{|l|}{ Other academic engagement } \\
\hline Academic intentions (mean /7) & 6.00 & 1.09 & -1.13 & .47 & .78 \\
\hline Class participation (mean /7) & 5.73 & 1.08 & -.58 & -.58 & .81 \\
\hline Enjoyment of school (mean /7) & 5.43 & 1.38 & -1.00 & .94 & .90 \\
\hline Academic buoyancy (mean /7) & 5.11 & 1.33 & -.60 & -.02 & .81 \\
\hline Relationship teachers (mean /7) & 5.48 & 1.34 & -.93 & .53 & .87 \\
\hline Homework completion (mean /7) & 4.38 & 0.90 & -1.35 & .90 & - \\
\hline \multicolumn{6}{|l|}{ Home and parent factors } \\
\hline Home Resources (mean / 12) & 9.21 & 1.93 & -.33 & -.51 & .64 \\
\hline In-home help (mean /5) & 2.52 & 1.61 & .02 & -1.09 & .70 \\
\hline Out-of-home help (mean /6) & 2.31 & 1.62 & .53 & -.07 & .61 \\
\hline Parenting Style (mean / 14) & 10.60 & 2.33 & -1.00 & .16 & .69 \\
\hline School involvement (mean /7) & 2.49 & 1.67 & .84 & .68 & .61 \\
\hline
\end{tabular}

Note: Homework completion is 1 item and thus, reliability cannot be computed.

schoolwork'), planning (e.g., 'I try to plan things out before I start working on my homework or assignments'), and task management (e.g., 'When I study, I usually try to find a place where I can study well'). Impeding/maladaptive cognitive dimensions include anxiety (e.g., 'I worry about failing exams and assignments'), failure avoidance (e.g., 'Often, the main reason I work at school is because I don't want people to think bad things about me'), and uncertain control (e.g., 'When I get a good mark, I'm often not sure how I'm going to get that mark again'). Maladaptive behaviours include selfhandicapping (e.g., 'I sometimes put assignments and study off until the last moment, so I have an excuse if I don't do so well') and disengagement (e.g., 'I've pretty much given up being involved in things at school'). Each of these 11 factors includes four items - hence the MES-HS is a 44-item instrument. For each item, students rated themselves on a scale of 1 (Strongly disagree) to 7 (Strongly agree). The MES-HS has demonstrated a sound factor structure, comprising reliable dimensions (Cronbach's $\alpha$ ranging between .70 and .90 ) that are approximately normally distributed, 
significantly associated with literacy, numeracy and achievement at school, and sensitive to age and gender-related differences in motivation and engagement (Green et al., 2007; Martin, 2001, 2003d, 2007, 2008b). Distribution and reliability statistics for this study are presented in Table 1 (and detailed in Results).

Additional academic engagement measures. In order to develop a wider understanding of the outcome variables examined in this study, additional academic engagement measures were administered to students. Specifically, students were asked about their enjoyment of school (e.g., 'I enjoy being a student'), class participation (e.g., 'I participate in class activities'), academic intentions (e.g., 'I'd like to continue studying or training after I complete school'), academic buoyancy (e.g., 'I don't let a bad mark affect my confidence'), and teacher-student relationships (e.g., 'In general, I get along with my teachers'). Each of these factors comprised four items and were rated on a scale of 1 (Strongly disagree) to 7 (Strongly agree). An additional single-item engagement measure administered to students asked about homework completion (e.g., 'How often do you do and complete your homework and assignments?') and was assessed on a 1 (Never) to 5 (Always) rating scale. Similar to the MES-HS, these factors have demonstrated a sound factor structure and comprise reliable dimensions (Cronbach's $\alpha$ ranging between .80 and .90) that are approximately normally distributed and significantly associated with outcomes at school (Green et al., 2007; Martin, 2007, 2008a; Martin \& Marsh, 2006, 2008a, 2008b). Distribution and reliability statistics for this study are presented in Table 1 (and detailed in Results).

\section{STATISTICAL ANALYSIS AND CALCULATION OF SUBSCALE SCORES}

Before conducting the central analyses, it was important to first test the reliability of the measures by way of Cronbach's $\alpha$ using SPSS for Windows (Version 14, SPSS Inc, 2007). On the basis of reliable factors (see Table 1), subscale scores were calculated through deriving the mean of component items for the MES-HS and additional engagement measures - thus generating 17 subscale scores consistent with the eleven factors in the MES-HS and the 6 additional engagement measures. Each subscale score was retained on its original scale of measurement, thereby yielding a mean $/ 7$ for each score. A 1-7 rating scale for home and parent items was not feasible because most items (e.g., whether there is a computer at home) could only generate a Yes or No answer. For home and parent factors on the Yes/No dichotomous scale, a count was performed for each subscale such that, for example, the number of times a student responded 'Yes' to home resource items yielded that student's total home resource score. Once the various subscale scores were formed, the distributional properties of the measures were assessed by way of standard deviations (SDs), skewness, and kurtosis (see Table 1).

Following analysis of these descriptive properties, correlations (Pearson for continuous data and Spearman for categorical data) and hierarchical multiple linear regressions were performed using SPSS for Windows (Version 14, SPSS Inc, 2007). Correlations were conducted to gain a first sense of the relationships between home, parent, demographic, and achievement motivation factors. Then, hierarchical multiple linear regression analyses were conducted to ascertain the relative salience of proposed factors in predicting students' achievement motivation. In the present study, demographics were entered as the first step (we recognise gender and ethnicity as categorical and include them as would dummy variables be included in regression 
Marianne Mansour and Andrew J. Martin

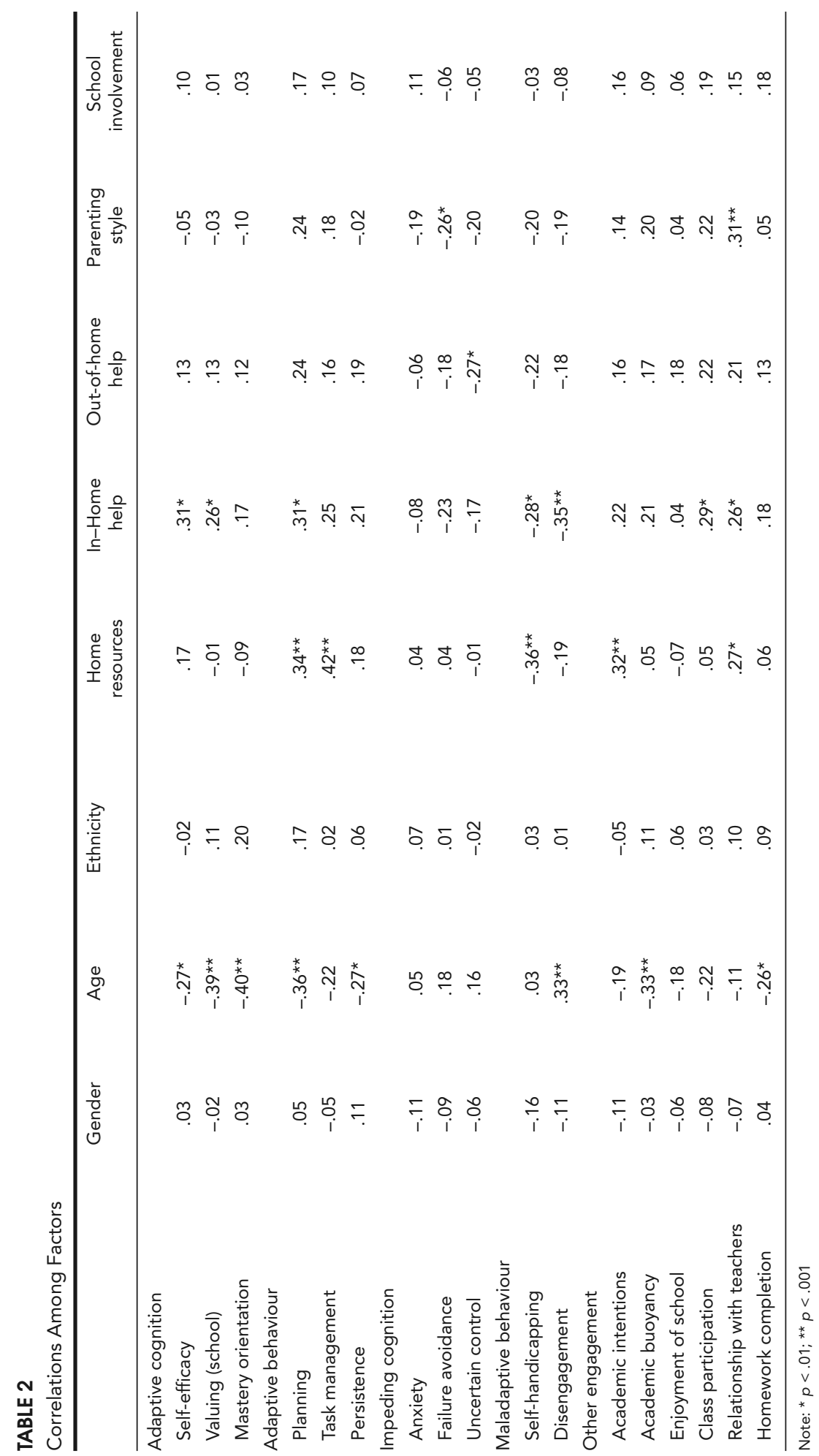

118 The Australian Educational and Developmental Psychologist

https://doi.org/10.1375/aedp.26.2.111 Published online by Cambridge University Press 
analyses; Tabachnick \& Fidell, 2007) and then in the next step, the home and parental factors were entered to determine the additional variance explained by the home and parental factors. The change in $\mathrm{R}^{2}$ (explained variance) from one step to another provides direct tests of variable sets in which the researcher is substantively interested (see Hair, Anderson, Tatham \& Black, 1995; Norusis, 1994; Tabachnick \& Fidell, 2007).

\section{SIGNIFICANCE LEVELS}

The reader is urged to be mindful that multiple statistical analyses are conducted and the sample is not overly large relative to these tests. When this is the case, there is a risk of Type I error. A conservative Bonferroni correction (e.g., see Tabachnick \& Fidell, 2007) was calculated to determine the risk of Type I error by dividing the $p$-value of 0.05 by the number of outcome variables (16), yielding a revised significance criterion level of .003 (rounded). On the one hand, this suggests focusing on findings at $p<$ .001; however, on the other hand is advice by Stevens (2001) suggesting that significance values less than $p<.01$ present a danger of Type II error. Accordingly, balancing Type I and II error, we set the significance level at $p<.01$.

\section{Results and Discussion}

\section{DESCRIPTIVE AND PSYCHOMETRIC PROPERTIES}

Descriptive analyses comprised a set of procedures assessing scale means and variances (SDs), analysis of distributional properties, and reliability coefficients. Findings are presented in Table 1. Mean levels are consistent with prior research (Green et al., 2007; Martin, 2007; Martin \& Marsh, 2006, 2008a, 2008b) and variances associated with each subscale are proportional and also in line with prior findings (Green et al., 2007; Martin, 2007; Martin \& Marsh, 2006, 2008a). The distributional properties of subscales approximate a normal distribution as indicated by relatively low skewness and kurtosis values.

Motivation and engagement measures are reliable, as indicated by Cronbach's alphas. Exceptions are the home and parent factors. In relation to this, it is important to note that these were dichotomous items leading to relatively truncated variance that attenuates inter-item correlations. With the inter-item correlations lower than would be the case on a richer rating scale, reliabilities were slightly lower. However, although a little low and suggesting a need for some caution when interpreting findings, the dichotomous nature of the rating scales involved, suggests the reliability on home and parental factors can be considered minimally acceptable.

\section{CORRELATIONS AND HIERARCHICAL LINEAR REGRESSIONS}

The associations between (a) demographics, home, and parent factors and (b) MESHS factors were first tested through correlations. These correlations are presented in Table 2. The broad pattern of findings here suggests that higher levels of home and parental support are associated with higher levels of adaptive motivation and lower levels of impeding and maladaptive motivation. Associations between (a) demographics, home, and parent factors and (b) additional engagement measures were also tested through correlations. These findings are in Table 2. As with MES-HS findings, the broad pattern here is that higher levels of home and parental support are associated with higher levels of adaptive motivation and engagement.

Hierarchical multiple linear regressions were conducted to examine the extent to which demographic and home factors predict motivation and engagement factors. As 


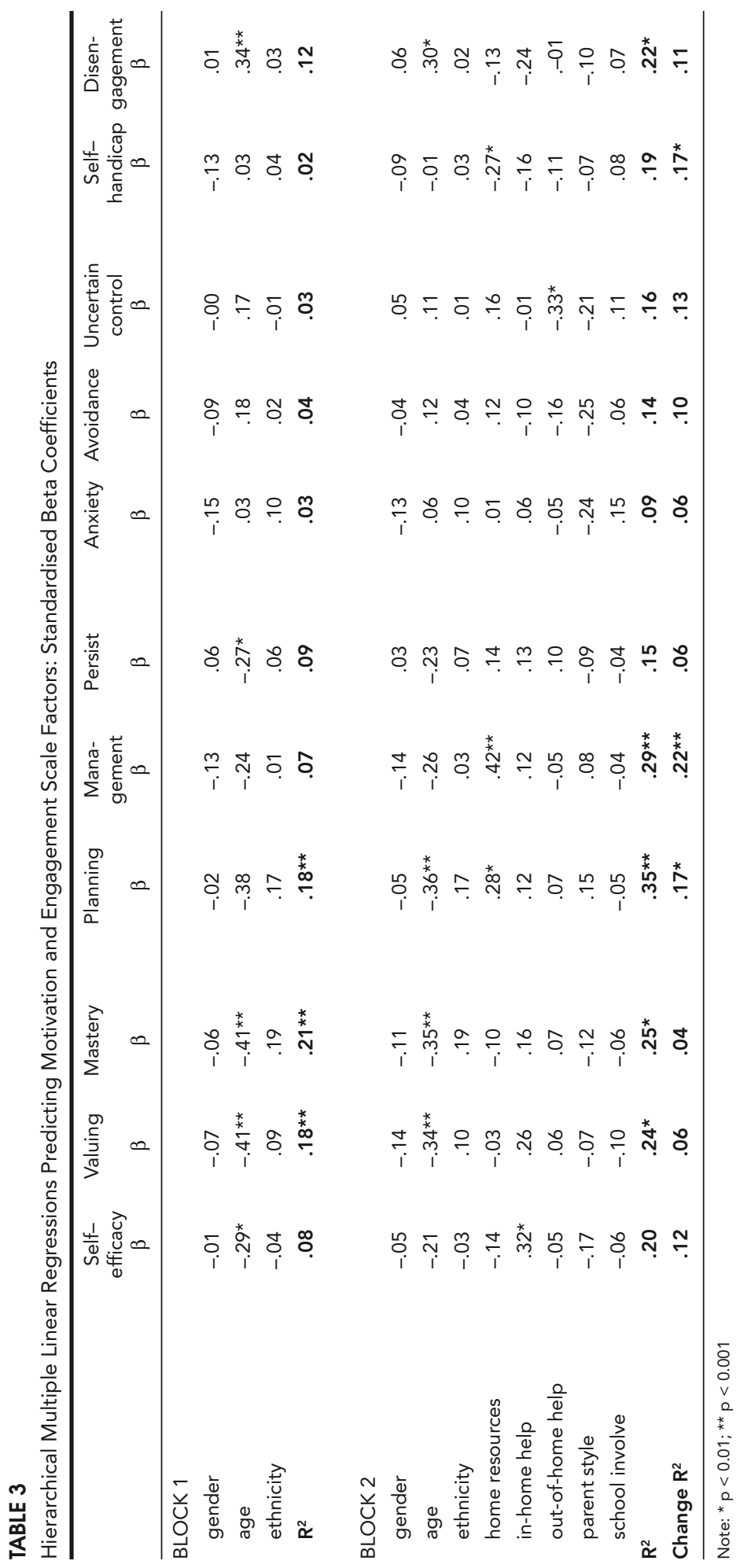


described previously, in the first step, demographic factors were entered. In the second step, home and parental factors were entered. As shown by $\mathrm{R}^{2}$ in Tables 3 and 4 , the set of demographic factors (via age) significantly predicted valuing, mastery, planning, and academic buoyancy such that older students tend to report lower levels on these dimensions. However, of greater importance to this study is the contribution of home and parental factors over and above demographic factors - these are assessed in the second step (Block 2). As indicated by the change in $\mathrm{R}^{2}$ values in Tables 3 and 4 , the home and parental set explained significant additional variance in planning, study management, self-handicapping, and teacher-student relationship.

\section{THE ROLE OF HOME AND PARENT FACTORS IN PREDICTING ACHIEVEMENT MOTIVATION}

The fact that the set of home and parental factors explained variance in some academic factors over and above demographics is central to the present study's understanding of factors relevant to achievement motivation. Indeed, this result is consistent with findings in previous research (Bassani, 2007; Darling \& Steinberg, 1993; DempseyHoover et al., 2005; Dweck, 1986; Gonzalez, 2002; Grolnick \& Slowiaczek, 1994). As such, it is again confirmed that home and parental factors are important for students' pathways to desirable academic outcomes. There is, then, merit in policy makers, researchers, and educators directing resources and energy to home and parent factors predictive of motivation and engagement (discussed further in applied implications below). What is particularly important about the present study is its identification of some of the specific home and parental factors that are salient in achievement motivation. Thus, in addition to demonstrating the relevance of home and parental factors as a set, it also points to what specific home and parental factors are and are not relevant. The findings also indicate what parts of achievement motivation are most associated with home and parent factors. Based on the present results, these are planning, task management, self-handicapping, and relationship with teachers. Nevertheless, before dismissing other motivation factors as unrelated to home and parental factors, additional research is needed to replicate these findings and to explore possible reasons why they are not significantly associated with the home.

Home resourcing was the factor most consistently linked to key aspects of motivation and engagement: positively with planning, task management, and negatively with self-handicapping - supporting prior work (Catan, 2004; Pomerantz \& Moorman, 2007), particularly Social Capital Theory (Bassani, 2007). Parenting style was positively and significantly associated with teacher-student relationships. Also illuminating, were the home and parental factors that did not map onto motivation and engagement. Parental involvement at school (i.e., non-home-based involvement) did not have any significant bearing on student motivation and engagement. It seems, then, that what happens within the home domain is a key to student motivation and engagement (Darling \& Steinberg, 1993; Dempsey-Hoover et al., 2005; Pomerantz \& Moorman, 2007). Hence, at the very least, it might be advisable for schools to promote and encourage ways parents can be involved in the home domain, even if parents do not actively engage with the school itself.

\section{APPLIED AND CONCEPTUAL IMPLICATIONS OF THE PRESENT FINDINGS}

From an applied perspective, the present study shows that home and parental factors are feasible factors to consider in the achievement motivation domain. In particular, 
home and parental factors that seem to have relatively greater relevance to student motivation and engagement are home resources and parenting style. Moreover, motivation and engagement factors that are relatively more likely to be relevant in intervention include planning, task management, self-handicapping, and relationship with teachers. Furthermore, the fact that different home and parental aspects are significant for different motivation and engagement factors, indicates the value of encouraging the development of a multiplicity of home and parental support roles. The findings also show that fostering students' motivation and engagement is not the sole domain of teachers and schools - parents are important to students' academic development as well (Dempsey-Hoover et al., 2005; Gonzalez, 2002; Grolnick \& Slowiaczek, 1994). Education, then, is a shared responsibility between parents, teachers, and schools.

From a conceptual perspective, the study's findings support the logic of incorporating the role of home and parents in achievement motivation theorizing. As discussed in the review of literature, the notions of parents and their relationship with their children as formulated by Social Capital Theory (Bassani, 2007) are supported in this study's finding of the role of home resources. The fact that home resources (e.g., a computer, a desk, a quiet place to study) were key in predicting all three of the significant motivation factors (planning, task management, self-handicapping) suggests the role of socio-economic and logistic advantage in school outcomes and points to the ongoing need for attention to access and equity efforts to assist disadvantaged students (Vinson, 2002). It is interesting that the motivation factors linked to home resources were all behavioural dimensions of the Motivation and Engagement Scale. Thus, the more logistic of home factors (i.e., home resources) were linked to the more logistic of motivation factors (i.e., behaviours such as planning, task management).

The importance of parenting style in teacher-student relationships is also noteworthy and consistent with contentions in theories of parenting style (e.g., Baumrind, 1966, 1991). Perhaps most pivotal is the finding that the nature and quality of relationships at home (as indicated by parenting style) are significantly linked to relationships with teachers at school. Of interest in subsequent research would be longitudinal research to get a sense of the causal ordering here. The role of connectedness in motivation, as articulated by Self-Determination Theory (Deci \& Ryan, 2000) is also borne out by the present study's results, particularly in relation to the link between parenting style and teacher-student relationships. As discussed earlier, connectedness refers to an individual's sense of security and positive attachment to significant others (Deci et al., 1991). It seems that a positive parenting style that encompasses emotional support and listening to the child (i.e., positive connectedness consistent with SDT) is also a factor relevant to the child's connection to his/her teacher. The present findings, then, align with and support psychoeducational theorising that has been influential in shaping research and practice for the past five decades.

\section{LIMITATIONS AND FUTURE DIRECTIONS}

There are limitations to the present study that have implications for future research in this area. The instrument was based on students' self-reports and perceptions about home, parents, and achievement motivation. Future work needs to test these issues using more 'objective' measures including, for example, parent and teacher reports. 


\section{TABLE 4}

Hierarchical Multiple Linear Regressions Predicting Additional Engagement Measures: Standardised Beta Coefficients

\begin{tabular}{|c|c|c|c|c|c|c|}
\hline & $\begin{array}{c}\text { Academic } \\
\text { intentions } \\
\beta\end{array}$ & $\begin{array}{c}\text { Class } \\
\text { participation } \\
\beta\end{array}$ & $\begin{array}{c}\text { Enjoy } \\
\text { school } \\
\beta\end{array}$ & $\begin{array}{c}\text { Academic } \\
\text { buoyancy } \\
\beta\end{array}$ & $\begin{array}{c}\text { Relationship } \\
\text { teachers } \\
\beta\end{array}$ & $\begin{array}{c}\text { Homework } \\
\text { complete } \\
\beta\end{array}$ \\
\hline \multicolumn{7}{|l|}{ Block 1} \\
\hline Gender & -.20 & -.10 & -.11 & -.04 & -.11 & -.03 \\
\hline Age & -.23 & -.23 & -.19 & $-.33^{\star \star}$ & -.13 & -.27 \\
\hline Ethnicity & -.06 & .03 & .07 & .10 & .11 & .09 \\
\hline $\mathrm{R}^{2}$ & .08 & .06 & .05 & $.12^{\star}$ & .04 & .08 \\
\hline \multicolumn{7}{|l|}{ Block 2} \\
\hline Gender & -.21 & -.14 & -.14 & -.06 & -.14 & -.04 \\
\hline Age & -.20 & -.14 & -.15 & $-.32^{\star}$ & -.09 & -.20 \\
\hline Ethnicity & -.05 & .00 & .05 & .10 & .10 & .08 \\
\hline Home resources & .27 & -.07 & -.15 & .04 & .14 & .03 \\
\hline In-home help & .15 & .18 & -.06 & .04 & .14 & .13 \\
\hline Out-home help & .01 & .12 & .26 & .06 & .11 & .04 \\
\hline Parent style & .04 & .16 & .06 & .20 & $.24^{\star}$ & -.01 \\
\hline School involve & .03 & .05 & -.06 & -.06 & -.03 & .11 \\
\hline $\mathbf{R}^{2}$ & $.21 *$ & .16 & .10 & .17 & $.21 *$ & .12 \\
\hline Change $\mathrm{R}^{2}$ & .13 & .10 & .05 & .05 & $.17^{*}$ & .04 \\
\hline
\end{tabular}

Note: ${ }^{\star} p<.01 ;{ }^{* *} p<.001$

There is also a need to extend the research beyond the sphere of achievement motivation and collect data on achievement itself. This can be conducted through the inclusion of literacy and numeracy items within the instrument or by accessing standardised national testing (e.g., NAPLAN; Ministerial Council on Education, Employment, Training and Youth Affairs, 2007). Some measures in the study were a little low in reliability. Although this can be the case with dichotomous rating scales (inevitable in this study using items about availability of computers in the home etc.), findings must be interpreted accordingly.

It is also important to recognise that the number of students involved in the study was relatively small, limiting statistical power. Future research would do well to access a larger sample in order to confirm the findings of the present study. Further, participants were in school in the western suburbs of Sydney, an area encompassing diverse socio-economic characteristics that might explain significant variance attributable to home resources. Expanding the sample to capture larger numbers of distinct socio-economic profiles would shed additional light on the predictive utility of factors such as home resources. Indeed, larger samples would enable researchers to move from scale score regression analyses to multi-item latent variable modelling (e.g., see Jöreskog \& Sörbom, 2006). Including a wider range of schools would also be an opportunity to extend analyses and conclusions. For example, with more schools, researchers can harness more sophisticated analyses such as multi-level modelling that can assess school effects over and above student and home effects (see Bryk \& Raudenbush, 1992; Goldstein, 2003). Finally, the present study utilised a crosssectional design and so no causal ordering of home factors over motivation factors 
could be established. Future research should be conducted over time, to establish what factors in one year are predictive of factors in the next.

\section{Conclusion}

The research presented here supports the finding that home and parental factors may be influential in predicting student motivation and engagement and suggests specific areas for future research. The study also provides direction as to the home and parental factors that are associated with achievement motivation, as well as the aspects of achievement motivation with which these home and parental factors are most significantly aligned. Taken together, the study provides information for educators and psychologists seeking to enhance students' educational outcomes, for parents looking to ways they can assist this process, and for researchers aiming to measure and examine the multiple factors relevant to students' academic motivation and engagement.

\section{Acknowledgment}

We would like to express our thanks to the high schools (including Delany College, under Mr Peter Wade) and the Catholic Education Diocese of Parramatta (and Dr John DeCourcy) who participated in this research.

\section{Endnote}

1 The term 'parent' is used to refer to parents and home-based caregivers alike.

\section{References}

Australian Bureau of Statistics. (2006). Children's participation in cultural and leisure activities, Australia. Retrieved September 7, 2008, from http: //www.abs.gov.au/ausstats/abs@.nsf/mf/4901.0

Bassani, C. (2007). Five dimensions of Social Capital Theory as they pertain to youth studies. Journal of Youth Studies, 10, 17-34.

Baumrind, D. (1966). Effects of authoritative parental control on child behavior. Child Development, 37, 887-907.

Baumrind, D. (1991). The influence of parenting style on adolescent competence and substance use. Journal of Early Adolescence, 11, 56-95.

Bryk, A.S., \& Raundenbush, S.W. (1992). Hierarchal linear models. Newbury Park, CA: Sage.

Catan, L. (2004) Becoming adult: Changing youth transitions in the 21st century: A synthesis of findings from the ESRC research programmes. Youth, citizenship and social change 1998-2003. Brighton: Trust for the Study of Adolescence.

Cohen, D., Dibble, E., \& Grawe, J. (1977). Parental style - mothers' and fathers' perceptions of their relations with twin children. American General Psychiatry, 34, 445-451.

Coll, G., \& Magnuson, K. (1997). The academic achievement of adolescents from immigrant families: the roles of family background, attitudes and behaviour. Child Development. 68, 351-363.

Darling, N., \& Steinberg, L. (1993). Parenting style as context: An integrative model. American Psychologist, 113, 487-496.

Deci, E.L., \& Ryan, R.M. (2000). The darker and brighter sides of human existence: Basic psychological needs as a unifying concept. Psychological Inquiry, 11, 319-338.

Deci, E.L., Vallerand, R., Pelletier, L., \& Ryan, R. (1991). Motivation and education: The selfdetermination perspective. Educational Psychologist, 26, 325-346.

Dempsey-Hoover, V., Walker, J., Sandler, H., Whetsel, D., Green, C., Wilkins, A., \& Closson, K. (2005). Why do parents become involved? Research findings and implications. The Elementary School Journal, 106, 105-125. 
Duran, B., \& Weffer, R. (1992). Immigrants' aspirations, high school process, and academic outcomes. American Educational Research Journal, 29, 161-181.

Dweck, C.S. (1986). Motivational processes affecting learning. American Psychologist, 41, 1040-1048.

Feuerstein, A. (2007). School characteristics and parental involvement: Influences on participation in children's schools. Journal of Educational Research, 94, 1-29.

Fuchs, T., \& Wobmann, L. (2005). Computers and student learning: Bivariate and multivariate evidence on the availability and use of computers at home and at school. Institute for Economic Research at the University of Munich. Working Paper No. 8, 1-29.

Gigliotti, R. J., \& Brookover, W. B. (1975). The learning environment: A comparison of high and low achieving elementary schools. Urban Education, 10, 245-261.

Glick, E., \& Marriot, B. (2007). Academic performance of young children in immigrant families: The significance of race, ethnicity, and national origins. The International Migrant Review, 41, 371-403.

Goldstein, H. (2003). Multilevel statistical models. London: Edward Arnold.

Gonzalez, A. (2002). Parental involvement: Its contribution to high school students' motivation. Urban Education, 75, 132-135.

Green, J., Martin, A.J., \& Marsh, H.W. (2007). Motivation and engagement in English, mathematics and science high school subjects: Towards an understanding of multidimensional domain specificity. Learning and Individual Differences, 17, 269-279.

Grolnick, W., \& Slowiaczek, M. (1994). Parents' involvement in children's schooling: A multidimensional conceptualisation and motivational model. Child Development, 65, 237-252.

Hair, J.F., Anderson, R.E., Tatham, R.L., \& Black, W.C. (1995). Multivariate data analysis. Chicago, IL: Prentice.

Jacobs, J. E., Lanza, S., Osgood, W. D., Eccles, J. S., \& Wigfield, A. (2002). Changes in children's selfcompetence and values: Gender and domain differences across grades one through to twelve. Child Development, 73, 509-527.

Jöreskog, K.G. \& Sörbom, D. (2006). LISREL 8.80. Chicago: Scientific Software International.

MacDonald, A., Saunders, L., \& Benfield, P. (1999). Boys' achievement progress, motivation and participation: Issues raised by the recent literature. Slough, UK: National Foundation for Educational Research.

Martin, A.J. (2001). The Student Motivation Scale: A tool for measuring and enhancing motivation. Australian Journal of Guidance and Counselling, 11, 1-20.

Martin, A.J. (2002). Motivation and academic resilience: Developing a model of student enhancement. Australian Journal of Education, 14, 34-49.

Martin, A.J. (2003a). Boys and motivation: Contrasts and comparisons with girls' approaches to schoolwork. Australian Educational Researcher, 30, 43-65.

Martin, A.J. (2003b). Enhancing the educational outcomes of boys: Findings from the ACT investigation into boys' education. Youth Studies Australia, 22, 27-36.

Martin, A.J. (2003c). The relationship between parents' enjoyment of parenting and children's school motivation. Australian Journal of Guidance and Counselling, 13, 115-132.

Martin, A.J. (2003d). The Student Motivation Scale: Further testing of an instrument that measures school students' motivation. Australian Journal of Education, 47, 88-106.

Martin, A.J. (2004). School motivation of boys and girls: Differences of degree, differences of kind, or both? Australian Journal of Psychology, 56, 133-146.

Martin, A.J. (2007). Examining a multidimensional model of student motivation and engagement using a construct validation approach. British Journal of Psychology, 77, 413-440.

Martin, A.J. (2008a). Enhancing student motivation and engagement: The effects of a multidimensional intervention. Contemporary Educational Psychology, 33, 239-269.

Martin, A.J. (2008b). The Motivation and Engagement Scale. Sydney, Australia: Lifelong Achievement Group (www.lifelongachievement.com).

Martin, A.J., Linfoot, K., \& Stephenson, J. (2000). Exploring the cycle of mother-child relations, maternal confidence, and children's aggression. Australian Journal of Psychology, 52, 34-40.

Martin, A.J., \& Marsh, H.W. (2006). Academic resilience and its psychological and educational correlates: A construct validity approach. Psychology in the Schools, 43, 267-282. 
Martin, A.J., \& Marsh, H.W. (2008a). Academic buoyancy: Towards an understanding of students' everyday academic resilience. Journal of School Psychology, 46, 53-83.

Martin, A.J., \& Marsh, H.W. (2008b). Workplace and academic buoyancy: Psychometric assessment and construct validity amongst school personnel and students. Journal of Psychoeducational Assessment, $26,168-184$.

Ministerial Council on Education, Employment, Training and Youth Affairs. (2007).National Assessment Program. (2007). Retrieved October 15, 2008, from http: //www.naplan.edu.au/reporting_naplan_ 2008/reporting_naplan_2008.htm.

Norusis, M.J. (1994). SPSS: Professional statistics. Chicago, IL: SPSS Inc.

Organisation for Economic Co-Operation and Development (OCED). (2001). Programme for international student assessment (PISA) in brief: Highlights from the full Australian report. Melbourne, Australia: ACER.

Organisation for Economic Co-operation and Development (OECD; 2006). Student questionnaire for PISA 2006. Paris: OECD.

Pintrich, P.R. (2000). Educational psychology at the millennium: A look back and a look forward. Educational Psychologist, 35, 221-226.

Pintrich, P.R. (2003). A motivational science perspective on the role of student motivation in learning and teaching contexts. Journal of Educational Psychology, 95, 667-686.

Pomerantz, E., \& Moorman, E. (2007). The how, whom and why of parents' involvement in children's academic lives: More is not always better. Review of Educational Psychology, 77, 373-410.

Rowe, K.J., \& Rowe, K.S. (1999). Investigating the relationship between students' attentive-inattentive behaviours in the classroom and their literacy progress. International Journal of Educational Research, 31, 1-138.

Ryan, M., \& Deci, E. (2000). Self-determination theory and the facilitation of intrinsic motivation, social development, and well-being. American Psychologist, 55, 68-78.

SPSS Inc. (2007). Statistical package for the social sciences (SPSS) for windows, Version 14 [Computer software]. Chicago, IL: SPSS Inc.

Stevens, J.P. (2001). Applied multivariate statistics for the social sciences (4th ed.). Hillsdale, NJ: Lawrence Erlbaum.

Tabachnick, B.G., \& Fidell, L. S. (2007). Using multivariate statistics. Boston: Allyn and Bacon.

U.S. Department of Education. (2003). National centre for education statistics, parent and family involvement in education survey of the 2003 national household education surveys program (PFNNHES: 2003).

Vinson, T. (2002). Inquiry into the provision of public education. Sydney: Pluto Press.

Weaver-Hightower, M. (2003). The 'boy turn' in research on gender and education. Review of Educational Research, 73, 471-498. 